\title{
Complementos de productividad en la función pública. Enseñanza de la experiencia internacional
}

Francisco Cardona Peretó $(*)$

Palabras clave: Función pública, visión crítica, sistemas de incentivos

Un creciente número de gobiernos buscan aumentar la motivación de los funcionarios y conseguir mejores resultados en la acción administrativa. Una de las soluciones más frecuentemente propuestas ha consistido en introducir primas de productividad u otros conceptos retributivos que liguen la totalidad o una parte de la remuneración final del empleado público a la cantidad o calidad del trabajo realizado y de los resultados conseguidos.

Este artículo adopta una actitud escéptica frente a esa solución porque tal propuesta no responde satisfactoriamente a las preguntas que hay que plantearse: ¿han funcionado realmente estas políticas retributivas? ¿Es la retribución ligada al desempeño un elemento motivador de una mejor gestión pública y de unos mejores resultados de la acción del Estado o de los servicios públicos? Las respuestas a estas preguntas son más bien negativas, si tenemos en cuenta la experiencia -ciertamente no satisfactoria- que de esas políticas y prácticas han tenido algunos países desarrollados.

\section{Las políticas salariales de los funcionarios como tema político}

En primer lugar, conviene echar una mirada rápida al contexto social, político y económico internacional en el que se plantean y desarrollan nuevas iniciativas para hacer una Administración pública más eficaz y eficiente, ya que esas iniciativas fundamentan esas nuevas políticas salariales en la función pública.

En algunos países de la OCDE, España incluida, se produjeron intentos, en los años 80 y 90, para introducir en la función pública la remuneración ligada al desempeño. Fue una reacción de los gobiernos frente a lo que

(*) Administrador Principal del Programa SIGMA de la OCDE. El Programa SIGMA es una iniciativa conjunta de la OCDE y la Unión Europea para la asistencia técnica en la reforma de la administración y la gestión públicas de los países de Europa Central y del Este. Está financiado principalmente por la Comisión Europea. Las opiniones expresadas en este artículo son personales del autor y no vinculan en absoluto a la Comisión Europea, a la OCDE, a sus países miembros, ni al Programa Sigma. 
se llamó «la crisis fiscal de Estado», una forma de denominar las consecuencias de la crisis económica que se estaba arrastrando desde mitad de los años 70. Los gobiernos entendieron que no se podía sustentar por mucho tiempo una presión fiscal creciente sobre los contribuyentes y se inspiraron en el sector privado para tratar de seguir prestando los mismos servicios sin aumentar impuestos. A los funcionarios se les dijo que tenían que hacer más cosas con menos recursos, que había que aumentar la productividad del aparato del Estado y que el dinero público tenía que aumentar sus rendimientos y producir mejores resultados ya que la demanda de servicios públicos no disminuía, sino que aumentaba al mismo tiempo que la cantidad de recursos públicos disponibles disminuía.

Este ambiente político condujo a muchos a abogar por formas de gestión pública mucho más parecidas a la gestión privada. Los procesos de trabajo tenían que ser revisados para hacerlos más eficientes a fin de que los funcionarios y empleados públicos produjeran más y mejores resultados. Estos postulados estuvieron en la base de lo que se vino en llamar la doctrina de la Nueva Gestión Pública, la cual se desarrolló sobre todo en el mundo anglosajón a finales de los 80 y la década de los 90 . Con anterioridad a esta doctrina de la Nueva Gestión Pública tuvieron lugar otras aproximaciones como, por ejemplo, el desarrollo del concepto de receptividad de la Administración pública a las nuevas demandas ciudadanas. La noción de receptividad se desarrolló sobre todo a finales de la década de los 70 y principios de los 80 para describir y subrayar la necesidad de que la Administración pública conectase mejor con las necesidades y demandas ciudadanas a fin de proveer mejores respuestas públicas a esas demandas y más ajustadas a ellas. Aunque la idea de receptividad es básicamente política, se propuso como un nuevo valor también para la función pública. La receptividad se tenía que verter en un concepto reforzado de responsabilización de todo el aparato estatal, incluida la función pública, pero también los partidos políticos y los que ocupasen puestos de designación política.

La idea de receptividad produjo no pocas frustraciones en los gestores públicos puesto que se les pedía mejores respuestas a los «clientes»de la administración dentro de unos marcos legales generalmente más diseñados para el control que para el servicio. La idea de receptividad no tuvo muy en cuenta que los servicios públicos dependen de las leyes, que otorgan derechos individuales (entitlements), frente a los cuales poco pueden hacer los gestores públicos para ser más receptivos a las demandas del público si no es proponer que se cambien las leyes, una decisión que corresponde a la política.

Para fundamentar la ideología de la Nueva Gestión Pública, la vieja idea anglosajona de accountability se reorientó y estrechó para pasar a denotar una noción más ligada a la idea de comprometerse con la obtención de resultados y objetivos programados por las organizaciones públicas. En consecuencia las remuneraciones de los individuos o grupos dentro de la organización tenían que basarse en una evaluación que sirviese para premiar o castigar financieramente el desempeño de los funcionarios. La consecuencia fue que una parte del salario de los funcionarios se ligó a los resultados individuales o de grupo.

En la Europa continental continuó prevaleciendo la idea clásica de responsabilidad, que estaba ya bien establecida por el Derecho administrativo, es decir, la idea de que los funcionarios y las Administraciones públicas han de responder de sus decisiones y actos frente al mundo exterior a través de una serie de mecanismos legalmente preestablecidos que garantizasen que esa rendición de cuentas fuese efectiva. Esas reglas jurídicas tenían que ser claras y precisas tanto desde el punto de vista sustantivo como procedimental. En esta línea, instrumentos como el control financiero interno y externo, el control de gestión y el control judicial de los actos administrativos o la institución del Defensor del Pueblo o similares adquirieron nuevos significados y se reforzaron como instrumentos para controlar a la administración, es decir, para obligar a la administración a rendir cuentas. Paralelamente, la idea de transparencia administrativa se afianzó en toda la UE -quizá fue la influencia de la entra- 
da en la UE de los países nórdicos- y se fue convirtiendo en una valor administrativo que finalmente se reflejó en la legislación de algunos países. Lo mismo está ocurriendo más recientemente con la idea de participación ciudadana en la toma de decisiones públicas y todo lo que la gestión de esa participación implica, entre otras cosas, una mayor responsabilización de los que toman decisiones públicas y una mayor apertura social de la administración.

Tanto diálogos doctrinales como verdaderas disputas ideológicas tuvieron lugar en la pasada década entre los defensores de la remuneración ligada al resultado y la performance y los defensores de una concepción que primase ante todo el principio de legalidad y la imparcialidad del funcionario, que se verían dañados si una parte de su salario se hiciese depender de decisiones, sesgadas de subjetivismo, de sus superiores administrativos o políticos. La nueva formulación de la idea anglosajona de accountability mostraba un interés prioritario por los resultados de la gestión pública. Para enfatizar esta dimensión, sus defensores tendieron a reducir o incluso a despreciar los aspectos procedimentales de la toma de decisiones pública. Los únicos procedimientos buenos serían los que sirven y son eficaces para la producción de resultados, es decir, que los procedimientos administrativos no pueden considerarse más que como meros instrumentos para obtener resultados.

Esta concepción instrumental del procedimiento administrativo implica que, como ocurre con cualquier otro instrumento o herramienta, su uso debe depender de los resultados a conseguir. Esta doctrina ha impregnado buena parte del discurso político y académico y también ha afectado a muchas áreas de gestión pública, no siempre para bien. Efectivamente, el desprecio al procedimiento ha llevado a no pocos escándalos de corrupción o de uso impropio de fondos públicos. Igualmente ha llevado a algunos gestores públicos a prescindir de elementos formales cruciales en la gestión de recursos humanos públicos, como la selección de funcionarios basada en el mérito y la competición, dando lugar a nuevas formas de clientelismo personal o político.

En general la práctica de las administraciones de la Europa continental continuó mayoritariamente anclada en la noción clásica de responsabilidad administrativa y su interés continuó centrándose en la importancia de garantizar la regularidad y la seguridad jurídica en la acción pública. La regularidad, previsibilidad y seguridad jurídica se consideran en muchos países continentales como los mejores valores sociales que puede producir la Administración pública ya que, solamente si esos valores son percibidos por la ciudadanía, se podrá fortalecer la confianza de los ciudadanos en la acción administrativa. Esa confianza ciudadana es uno de los resultados más buscados por los políticos en las sociedades democráticas, si bien es verdad que la preocupación por los resultados de la gestión pública también forma parte de ese componente de confianza y que la eficiencia pública no puede ser descartada como resultado a conseguir.

Estos debates tuvieron lugar básicamente en los países de la OCDE mientras que en el este del continente europeo un puñado de países estaban tratando de crear instituciones democráticas nuevas que reemplazasen al periclitado régimen comunista. Entre estas instituciones nuevas que debían crearse aparecía en lugar muy destacado la creación de una función pública profesional, despolitizada e imparcial, lo que no sólo marcaría un fuerte contraste con el antiguo régimen sino que, además, era una condición necesaria para un día devenir miembros de la Unión Europea, tal como se les dijo a esos países por los gobiernos de la UE en su cumbre de Madrid de 1995, donde se concretizaron más los llamados criterios de Copenhague de 1993. El esfuerzo reformista en esos países también se dirigió prioritariamente a la creación de procedimientos de decisión pública administrativa controlables tanto desde el punto de vista de la seguridad jurídica y garantías de los derechos individuales -las decisiones administrativas en el antiguo régimen tenían un fuerte componente de arbitrariedad-como desde el punto de vista del control financiero público. 
En los países emergentes del comunismo, sus gobiernos democráticos trataban de luchar contra una crisis económica sin precedentes con una base fiscal tan débil que no podían pensar seriamente -al menos en el corto plazo- en la creación de una función pública suficientemente bien pagada como para hacerla mucho más profesional. A esto se unía el desprestigio social de los funcionarios, la mayoría de los cuales habían servido en el período comunista y eran considerados como poco menos que parásitos sociales. A esto habría que añadir el desprestigio social de toda idea de sindicación. Los sindicatos estaban completamente desprestigiados por su antiguo carácter oficialista y no tenían ninguna fuerza sociopolítica. Esto dejó el sistema político sin ningún contrapoder social significativo que concurriese en la definición de las reformas de la administración y de la función pública.

Finalmente, otro elemento concurrente en la escena pública post-comunista eran los políticos que habían abrazado sin más las teorías más radicales del capitalismo liberal, así como antiguos comunistas reconvertidos. Muchos de esos nuevos políticos habían regresado del exilio, que en su mayoría habían pasado en países de habla inglesa, y no pocos estaban imbuidos de un cierto mesianismo salvador de sus antiguos compatriotas para lo que estaban dispuestos a aplicar recetas sobre las cuales se hablaba con pasión en sus países de exilio. Para solucionar el problema -definido como que los funcionarios eran comunistas corruptos y perezosos sin ningún espíritu de servicio público y mucha ansia de «servirse del público», lo cual no era del todo falso- la panacea, aparte del despido para «limpiar» la administración («lustración» se llamó a esa política), fue proponer que las remuneraciones de los funcionarios debían ser directamente dependientes de lo que trabajasen. Un sistema salarial que ofreciese salarios prefijados por ley era considerado como equivalente a la perpetuación de una administración anquilosada y un desincentivo para el cambio.

El discurso político populista estaba así servido. No hubo partido político en los 90 que, no importa en qué país del centro-este de Europa y en algunos del oeste, no contuviera en sus programas o manifiestos la intención de remunerar a los empleados públicos de acuerdo al desempeño, aparte de continuar «limpiando» políticamente o «adelgazando» económicamente el Estado. Lo primero «《limpieza»o «lustración»- era un requisito político interno derivado de las luchas de poder y encaminado a expulsar de la administración pública a los más activos colaboradores del régimen comunista. La lustración se llevó a cabo con diferente grado de intensidad según los países. Lo segundo -«delgazamiento»- era generalmente una imposición externa, especialmente de las instituciones financieras internacionales, que en la época todavía aplicaban a rajatabla el llamado «consenso de Washington».

En conclusión, la introducción de complementos de productividad y, consecuentemente, la evaluación del desempeño, se convirtió en una de las políticas más populares en la región este de Europa, cuyos gobiernos reformadores copiaban acríticamente las modas anglosajonas que unos y otros predicaban. Estas opciones políticas se introdujeron en las leyes de función pública que todos los países promulgaron en la década de los 90 y principios de la de 2000. Ni que decir tiene que no existían los instrumentos ni la capacidad de gestión para evaluar más o menos creíblemente el desempeño de los funcionarios. En esas condiciones la arbitrariedad en la asignación de salarios se convirtió en una práctica bastante generalizada, con efectos muy perversos para el objetivo de profesionalización de una función pública imparcial.

Los gobiernos del oeste de Europa, y en general los anglosajones dentro de la OCDE, continuaron proponiendo los postulados básicos de la Nueva Gestión Pública, la paga ligada al desempeño, la relajación o anulación de los procedimientos formales de toma de decisiones, y en definitiva la debilitación de controles «innecesarios» sobre los gestores públicos todo ello con el objetivo de obtener resultados eficientes y «value for money». Muchos consultores internacionales también empujaban para la introducción de esas ideas en las nuevas democracias del centro europeo o incluso más allá, en el mundo económicamente subdesarrollado. 


\section{La remuneración del desempeño en los países de la OCDE}

Antes de la década de los 80, la mayoría de los funcionarios públicos en los países OCDE tenían sistemas salariales que remuneraban el puesto de trabajo con independencia de cómo lo desempeñara su ocupante. El sistema se basaba en una valoración del puesto de trabajo ligada a la descripción del puesto y al grado. Para ello se usaban diferentes técnicas y métodos tanto analíticos como no analíticos o una combinación de ambos. El sistema se completaba con un énfasis en la antigüedad en el servicio, la cual se consideraba como un mérito significativo para avanzar en la carrera profesional, y que se remuneraba como un «saber hacer» que la experiencia profesional debería garantizar.

A finales de los 80 y en los 90 una serie de países intentaron reducir el peso de la antigüedad y de la valoración objetiva del puesto e incrementar la importancia de un componente salarial variable ligado al desempeño individual o de grupo, lo que llevó a experimentos de nuevos sistemas retributivos basados en estas nuevas preferencias políticas. En la vanguardia de los países que iniciaron ese proceso consistente en introducir diversas variantes de remuneración ligada al desempeño se encontraron Nueva Zelanda, Holanda y el Reino Unido. Algunos otros países iniciaron también tímidos movimientos en esa dirección, como fue el caso de Alemania, Australia, Austria, Dinamarca, España, Finlandia, Francia y Noruega. Canadá y los Estados Unidos habían tenido durante mucho tiempo una porción del salario ligada al desempeño para sus directivos públicos altos y medios. El resultado de estas innovaciones en materia salarial pueden distinguirse mejor si miramos por una parte a la función pública alta y media y por otra parte al resto de los funcionarios.

\section{Remuneración al desempeño para personal directivo}

Los países con una porción significativa de salario ligada al desempeño de sus altos y medios funcionarios actualmente incluyen Australia, Canadá, Dinamarca, Estados Unidos, Holanda, Irlanda, Reino Unido y Nueva Zelanda. La remuneración gerencial ligada al desempeño se ha usado sobre todo como una vía para reducir las diferencias retributivas de los directivos del sector público con respecto a los del sector privado, con el objetivo de atraer hacia la gestión pública y retener en ella a gestores procedentes del mundo privado. Este objetivo político se inscribía en una política más amplia tendente a introducir modos de gestión privados en la Administración y los servicios públicos.

Sin embargo, estas políticas crearon problemas de compatibilidad y coherencia interna con el sistema de remuneraciones establecido para los funcionarios en general. Los desequilibrios salariales creados en el interior de la Administración desencadenaron presiones de todo origen orientadas a conseguir una mayor igualación salarial dentro de la Administración. Hasta el momento no existen pruebas empíricas -salvo anecdóticas- concluyentes de que esa política empleada para atraer hacia la administración a gestores privados a través de remuneración al desempeño haya efectivamente contribuido a una mayor motivación de los funcionarios o a una mejor gestión pública. No se ha encontrado tampoco ninguna correlación entre remuneración del desempeño para los directivos de una parte y mejoras en el desempeño organizativo por otra. La mayoría de los informes -oficiales- de los países OCDE que remuneran el desempeño de sus gestores públicos apuntan a la conclusión de que tal política ha mostrado cierta utilidad para superar temporalmente presiones del mercado de trabajo originadas por la competencia del sector privado en la atracción de determinados grupos profesionales, pero sin que ese sistema de remuneración haya impactado realmente sobre el desempeño de los interesados en el puesto de trabajo. 


\section{Remuneración al desempeño para personal no directivo}

La idea de remunerar más a los que mejor y más trabajan tiene un gran atractivo intelectual por su impecable lógica y por la noción de justicia retributiva que encierra. Pero los sistemas empleados hasta ahora para hacer de esa idea un práctica de gestión en la Administración pública han producido, al parecer, pocos resultados satisfactorios.

Efectivamente, existen pocas evaluaciones de los efectos de la introducción de paga ligada al desempeño para personal no directivo dentro de la Administración pública. La mayoría de las evaluaciones disponibles se refieren a Australia, Estados Unidos y Reino Unido y son solamente parciales, es decir, analizan solamente una o dos organizaciones públicas. En conjunto, las -escasas- evaluaciones arrojan resultados que muestran ciertos fallos en el diseño o en el funcionamiento de los sistemas introducidos para la evaluación y remuneración del desempeño. Por ejemplo, las evaluaciones del Performance Management and Recognition System (PMRS) establecido en 1984 en Estados Unidos y suspendido en 1993, así como la evaluación del Inland Revenue Service Scheme del Reino Unido, concluyeron que la mayoría de los empleados nunca obtenían calificaciones superiores a «satisfactorio» en los ejercicios de evaluación del desempeño. Dado que sólo aquellos que alcanzasen una calificación de «sobresaliente» tenían derecho al plus de productividad, eso significaba que en la práctica muy pocos empleados podían obtener ese plus mientras que la mayoría, aun trabajando satisfactoriamente, no lo cobraban. La mayoría de las plantillas encontraban este sistema muy desmotivante, que provocaba celos profesionales, impedía la cooperación espontánea necesaria entre compañeros de trabajo, y todo ello llevaba al personal a poner en cuestión la legitimidad del sistema de evaluación del desempeño. Los directivos que administraban la evaluación del desempeño también eran de la opinión de que el sistema de paga por desempeño no había mejorado la motivación de la plantilla. Este tipo de resultados, ciertamente decepcionantes, también se pudieron encontrar en ciertas evaluaciones hechas en Australia (OECD/PUMA: 1997 a y b)

\section{Efectos secundarios de la paga ligada al desempeño}

Uno de los mayores problemas asociados con los sistemas de paga ligada al desempeño en la Administración pública, y lo mismo puede decirse de cualquier sistema de atribución más o menos discrecional de incentivos monetarios, es que -para evitar la desmotivación de la que hemos hablado antes- las presiones sobre los gestores hace que éstos tiendan a hacer evaluaciones con altas calificaciones y por tanto generando costes salariales más altos, incluso si hay límites de gasto de personal establecidos de antemano. Efectivamente, bajo la presión derivada del ansia de retener personal o de emplear más plantilla para superar puntas de trabajo, los gestores tienden a otorgar mejores calificaciones en la evaluación del desempeño, además de inventar cualquier artimaña para dar más salario a sus colaboradores, a veces de manera indiscriminada. Esto suele llevar a los empleados y a sus sindicatos a considerar el plus de productividad como una parte negociable del salario y a no colaborar con la dirección si no hay plus de productividad.

Otro problema importante está vinculado al hecho de que ningún sistema de evaluación del desempeño es totalmente objetivo, ya que por definición toda evaluación tiene un alto componente de subjetividad por parte de los evaluadores. En la Administración pública es muy fácil traspasar la fina línea que separa la subjetividad de la arbitrariedad. Si esto ocurre, si los empleados, el público o los medios de comunicación perciben que esa línea se ha traspasado y que la Administración pública se comporta arbitrariamente, es decir, con favoritismo, la legitimidad pública de la Administración queda muy dañada.

Desde un punto de vista teórico se podría decir que los aumentos en costes de personal como consecuencia de pagos de pluses de productividad podría financiarse, o incluso equilibrarse, por una mayor productividad 
efectiva, al igual que ocurre en las empresas de producción del sector privado. Sin embargo, medir la productividad en la Administración pública es muy problemático ya que no todas las actividades que realiza la Administración son mensurables en términos cuantitativos, aunque es verdad que en algunas áreas de servicio público se pueden establecer objetivos mensurables. En algunos países como Australia y el Reino Unido este tipo de objetivos se han llegado a negociar a nivel de organizaciones públicas concretas. Sin embargo, continúan apareciendo problemas derivados de la diferente capacidad que unas u otras organizaciones públicas tienen para determinar claramente cuáles serán sus objetivos de productividad y cómo generarán ahorros que permitan financiar los correspondientes pluses. Se intenta que los pluses de productividad sean neutrales en términos de coste, pero esto exige una capacidad de gestión muy sofisticada que al mismo tiempo garantice que los estándares de calidad y cantidad para el receptor final del servicio, el ciudadano, no se vean negativamente afectados.

Una de las conclusiones que se extraen de la experiencia de los países OCDE con los pluses de productividad es que esa técnica no está funcionando bien en ningún país. Además, la introducción de incentivos monetarios discrecionales ha generado efectos secundarios negativos difíciles de solucionar. A fin de atender a la insistencia de los políticos para introducir rápidamente esos incentivos monetarios, las unidades responsables de la gestión de recursos humanos en la Administración y los gerentes de los servicios finalistas han tenido que hacer una gestión más compleja y multiplicar sus actividades burocráticas para intentar mantener el sistema de pluses de productividad bajo control. En ese sentido podemos decir que la introducción de pluses de productividad aumenta directamente la carga burocrática de las Administraciones públicas.

Un relativamente reciente Libro Blanco del Gobierno de los Estados Unidos insistió en la introducción generalizada de la remuneración ligada al desempeño, si bien reconoce que «el éxito de los sistemas de remuneración ligados al desempeño depende principalmente de la calidad del sistema general de gestión que le sirve de base... Observadores informados de la gestión del gobierno federal convienen en que el rigor y la calidad de la gestión del desempeño -y su medición- en las agencias federales es desigual en el mejor de los casos» (United States White Paper: 64). A pesar de eso, la Oficina Federal de Gestión de Personal (OPM) creía llegado el momento de establecer un amplio marco para hacer discriminaciones en las remuneraciones en base al desempeño, con independencia de que las agencias estuviesen o no preparadas para gestionarlo. Una de las razones por las que la OPM insistía en ello era que el sector privado «vincula la remuneración al desempeño como una cuestión de principio», aunque constataba que los enfoques basados en la «gestión de la calidad totali se habían adoptado solamente en unas pocas empresas privadas que no vinculaban la remuneración al desempeño individual sino colectivo y que, además, la mayoría de esas empresas pertenecían al sector manufacturero o a otros sectores cuyas operaciones se centran en el ahorro de costes durante el proceso de producción. A pesar de todas esas constataciones, el Libro Blanco parecía tener pocas dudas para crear ese marco de gestión de la paga ligada al desempeño, a pesar de todas las insuficiencias que se reconocían. Todavía es pronto para evaluar el éxito o el fracaso de esa iniciativa, aunque hay muchos elementos para anticipar que ésta no será precisamente un éxito, y ya existen indicios de ello.

Casi al mismo tiempo, en mayo de 2002, se presentaron las conclusiones de un informe-encuesta realizada entre los países miembros de la UE sobre sus sistemas de remuneración ligados al desempeño ${ }^{2}$. Las conclusiones principales de este informe son, en síntesis, las siguientes:

2 «Survey for the $38^{\text {th }}$ Meeting of the Directors-General of the Public Service of the Member States of the European Union (La Rioja, Spain, 28-29 May 2002): Comparative Survey of the Systems of Productivity-linked Remuneration that are Employed in the Civil Services of Member States of the European Union (Performance-related Pay)》. European Institute of Public Administration, Maastricht, Spring 2002. Responsible of the Survey: Seán Fitzpatrick. 
- Los sistemas de remuneración ligados al desempeño son caros y su aplicación requiere mucho tiempo y energías. En muchos casos, sólo son aplicables para los directivos.

- En general, el porcentaje de salario atribuido a productividad es bajo en los países de la UE y la discreción de los directivos es relativamente pequeña.

- En muchos casos, el sistema se ha introducido como ejercicios experimentales con la intención de aplicarlos después más extensivamente. Sin embargo, a falta de análisis o evaluaciones rigurosos sobre los efectos de los proyectos experimentales, no está claro cómo se podrán aplicar a gran escala en la Administración.

- Casi ninguno de los sistemas aplicados hasta ahora tiene en cuenta a los funcionarios que no están a la altura de los desempeños requeridos. ¿Qué pasa con los funcionarios que no trabajan bien? No se prevén consecuencias para los que trabajan por debajo de los estándares requeridos.

- La medición del desempeño, en particular en áreas donde no existen indicadores claramente cuantificables, es extremadamente difícil o imposible.

- No se han encontrado pruebas concluyentes de que la introducción de salarios vinculados al desempeño se haya traducido en una mejora real del desempeño, en una mejora de la gestión de recursos humanos o en la calidad de los servicios públicos prestados.

- La paga de productividad en ningún caso se consideró por los funcionarios como algo especialmente motivante.

- Por el contrario, los diálogos regulares anuales entre los directivos y los funcionarios sobre el desempeño individual, la fijación de objetivos y la revisión de los del año anterior sí que se consideraron por los funcionarios como algo que tuvo efectos positivos sobre su motivación personal en el trabajo. Muchos lo consideraron como un reconocimiento de su contribución individual a los objetivos generales de la institución en la que trabajaban.

Un posterior estudio, de la OCDE (OECD/GOV 2005), basado en las respuestas oficiales dadas en 2004 por los gobiernos de 11 países miembros ${ }^{3}$ más Chile, concluye que:

- La introducción de remuneración ligada al desempeño plantea problemas de diseño y de aplicación, siendo los más importantes los asociados a la medición del desempeño y, especialmente, la realización de evaluaciones del personal.

- Hay obstáculos estructurales a la introducción de la paga ligada al desempeño como, por ejemplo, el subjetivismo, falta de transparencia, inadecuada delegación de competencias de gestión de personal, etc., que hacen muy difícil la confianza de los funcionarios en el sistema de evaluación del desempeño y su remuneración.

- La mayoría de los países examinados sitúan esa retribución variable para sus funcionarios entre un 5 y un $10 \%$ del total del salario de cada funcionario.

- El impacto de la remuneración al desempeño sobre la motivación de los funcionarios es muy poco o ninguno. Otras iniciativas parecen tener mucha más influencia sobre la motivación del personal, tales como un trabajo satisfactorio y una cierta perspectiva de desarrollo profesional o de carrera. La remuneración al desempeño colectivo o de grupo es más motivante que la individual, en todo caso.

- Los esquemas de remuneración ligada al desempeño, por el contrario, han producido resultados positivos como instrumento para los cambios organizativos y de procesos emprendidos por los directivos.

${ }^{3}$ Estos 11 países miembros de la OCDE fueron Alemania, Corea del Sur, Dinamarca, España, Finlandia, Francia, Hungría, Italia, Reino Unido, Suecia, y Suiza. 
Es decir que los sistemas de retribución ligada al desempeño no son motivantes para los funcionarios, a pesar de que ésta era la razón que más se había esgrimido para introducirlos, sino que más bien son un instrumento que sirve para aumentar el poder de los directivos públicos y, por tanto, indirectamente de los políticos. El efecto perverso que podrían tener es que, con el objetivo de aumentar el poder de dirección dentro de la Administración - para producir «cambios organizativos y de procesos», según la OCDE- se llegue a una mayor politización de la Administración pública si los funcionarios ven que una parte de su remuneración es variable y va a depender de la discreción de sus jefes, si bien es cierto que en la mayoría de los países de la OCDE, como se ha dicho antes, la franja se mantiene por debajo del 10\% de la remuneración total.

\section{Gestión del Desempeño, un nuevo enfoque}

El hecho de que la introducción de remuneración ligada al desempeño en la Administración pública no ha sido satisfactoria no tiene que necesariamente llevar a la conclusión de que es inherentemente imposible hacer que los funcionarios públicos respondan adecuadamente de la manera en que trabajan. Lo que quizás ha sido un error ha sido la importación ciega y acrítica de técnicas del sector privado, nacidas y desarrolladas a principios del siglo XX en el sector de producción industrial, hacia la administración pública.

Lo que realmente viene siendo un problema en las Administraciones públicas es la poca calidad de los servicios públicos prestados, especialmente de aquéllos servicios que tienen un alto contenido burocrático. Esto está también emparejado con una bastante generalizada falta de sensibilidad de los directivos hacia la obtención de resultados, hacia la eficiencia en el uso de los recursos públicos. La mejor solución para estas deficiencias no es la introducción de la remuneración ligada al desempeño. Quizás sería más efectivo a largo plazo el iniciar un proceso de transformación gradual hacia una cultura administrativa más preocupada por los resultados y el buen servicio al ciudadano.

Desde finales de los años 90 se viene observando una tendencia en los países de la OCDE hacia un enfoque más comprehensivo del problema. A este enfoque se le ha llamado «Gestión del Desempeño» (performance management) e implica bastante más cosas que la mera introducción de la remuneración vinculada al desempeño. Es demasiado pronto para evaluar si ese enfoque está funcionando bien o no. Los sistemas de Gestión del Desempeño buscan enlazar la gestión de los recursos humanos con objetivos y estrategias institucionales. En la práctica, los países que han tratado de establecer sistemas de gestión del desempeño (Australia, Canadá, Estados Unidos, Nueva Zelanda, Reino Unido...) han tenido dificultades para ligar coherentemente los objetivos del individuo, de la unidad administrativa y de la institución en su conjunto. En estos países existen hasta ahora escasas pruebas de buen funcionamiento del sistema. Por el contrario, lo que parece hacerse claro es que el desarrollo de técnicas muy formalizadas de gestión del desempeño, aparte de aumentar la burocracia, puede ser perjudicial para una cultura democrática de un servicio público más transparente.

Una de las mayores dificultades aparece, otra vez, en la medición. Los indicadores de desempeño son ya antiguos en el mundo de la gestión de las organizaciones públicas, si bien se han desarrollado en gran manera durante las dos últimas décadas. Muchos Tribunales de Cuentas u oficinas de auditoria pública externa han ensanchado sus competencias para ir más allá del control de legalidad e incluir el control de gestión, la eficiencia o la eficacia de los programas públicos en lo que se ha venido en llamar la auditoria del desempeño o auditoria de gestión. El uso más intensivo de indicadores de desempeño se ha dado en países anglosajones, donde la discreción de los directivos públicos es muy amplia. Ese uso ha sido más limitado en los países de Derecho administrativo, donde el compor- 
tamiento de la Administración está mucho más inspirado por las leyes y los reglamentos que por indicadores de gestión y donde la discreción de los directivos públicos está mucho más constreñida por normativas procedimentales. Los intentos de introducir una cultura del desempeño en ambos tipos de países han sido problemáticos y han producido pocos resultados hasta ahora.

Quizás la causa esté en que la gestión del desempeño tiene que basarse en una gestión estratégica en la que los objetivos y los resultados sean establecidos de manera coherente a través de varios procesos de decisión consecutivos y distintos y que se retroalimentan mutuamente. Estos procesos son: el proceso político, el de elaboración de políticas públicas y el de gestión pública. Eso hace difícil la introducción de enfoques de gestión pública estratégica en las organizaciones de la Administración pública, precisamente por el hecho de que «estrategia» no tiene el mismo significado para los políticos que para los gestores públicos.

Efectivamente, por ejemplo, los presupuestos públicos basados en el desempeño son un enfoque bastante racional para vincular los resultados a los recursos disponibles, pero la lógica económico-presupuestaria basada en el desempeño es diferente de la lógica política y ambas lógicas no son necesariamente convergentes. Una lógica económica estricta no representa la causa última de las decisiones políticas, puesto que los compromisos políticos pueden producir objetivos ambiguos así como resultados ambivalentes. Los objetivos políticos y los objetivos organizativos no son fáciles de reconciliar. Sin embargo, enfoques de gestión estratégica se han introducido en algunos países como Australia, Canadá, Finlandia (Strategic Portfolio Scheme, 1995-1999), Estados Unidos (Government Performance and Results Act_GPRA- de 1993), Nueva Zelanda (Strategic Results Areas and Key Results Areas Schemes), y Reino Unido (New Strategic Approach for Public Spending, 1998). En definitiva, como Pollit y Bouckaert sugieren «las dificultades fundamentales para evaluar algunas, si no todas, estas iniciativas estratégicas consisten en determinar hasta qué punto sirven para mejorar la calidad de las decisiones tomadas por los niveles altos de la administración, y si esos nuevos procesos de toma de decisiones llevan a resultados más eficientes o a mejores impactos de las acciones públicas» (Pollit y Bouckaert 2000: 120). Efectivamente, esto está lejos de estar garantizado.

\section{Capacidad gerencial y remuneración del desempeño}

Como hemos dicho anteriormente, la introducción en la función pública de la remuneración ligada al desempeño continúa ejerciendo un inmenso atractivo como un elemento para modernizar la gestión y la Administración pública. Muchos están realmente convencidos de que puede ser un instrumento eficaz para promover un mejor comportamiento y un mayor compromiso de los funcionarios con el servicio público. Nosotros hemos intentado mostrar cuan problemática esa introducción puede ser en la práctica, siempre dando por supuesto que los países de la OCDE que lo han introducido son los más ricos del planeta y cuentan con administraciones públicas muy capacitadas y consolidadas en términos de cantidad y calidad de sus funcionarios y de sus estructuras de gestión.

¿Qué puede ocurrir cuando las Administraciones públicas tienen menos capacidades técnicas y los países menos recursos? En algunos países del centro de Europa se ha regulado por ley- como consecuencia de planteamientos populistas a que nos hemos referido antes- la introducción de una parte variable del salario de los funcionarios vinculada a la evaluación del desempeño, pero carecen en general de la capacidad administrativa y de gestión necesaria para hacer evaluaciones creíbles de sus funcionarios. El resultado es que apenas se aplican esos 
preceptos legales. Además, han otorgado la posibilidad legal de que una gran proporción de la remuneración esté vinculada al desempeño.

Así, en Lituania puede llegar al 70 \% del salario. En Estonia la ley no fija límites y eso condujo a muchos abusos y arbitrariedades hasta el punto que la Suprema Oficina de Auditoria de Cuentas Públicas concluía en sus informes de 2001 y 2002 que la Administración no estaba preparada para gestionar un sistema de remuneración ligada al desempeño y ordenaba al Ministerio de Finanzas poner orden en el sistema. En Letonia se introdujeron en 1997 unos llamados «contratos de gestión» muy opacos en los que los salarios se vinculaban al desempeño y que llevaron a una significativa distorsión del sistema de función pública y de gestión pública que, tras muchos lances políticos, incluida la intervención del Tribunal Constitucional llevó a su abolición en enero de 2004. Para entonces ya se había causado mucho daño al sistema de gestión pública y a la credibilidad de la función pública. En Polonia la ley tampoco fija límites ni hay establecido un sistema creíble de evaluación de desempeño, lo que hace que la parte variable del salario sea completamente discrecional. En Eslovaquia solamente los funcionarios que son calificados como «muy satisfactorios» tienen derecho a un complemento de productividad y, como la mayoría reciben calificaciones de 'satisfactorio', casi nadie cobra el plus, lo que se traduce en un elemento de desmotivación. En Hungría la decisión del superior puede hacer variar el salario del funcionario en un más o en un menos 20\% más otras primas discrecionales. Según la ley checa, que entrará en vigor en 2007, es posible que la parte variable del salario de los funcionarios pueda oscilar entre un 60 y un 70\% del total y dependiente de la voluntad discrecional de los superiores jerárquicos del funcionario. Los demás países del centro de Europa han introducido también arreglos similares en su legislación, excepto, por el momento, Rumania. En Turquía tienen unos «fondos rotatorios» que provienen de los ingresos generados por el ministerio que se reparten entre los funcionarios, teóricamente en función de la evaluación del desempeño, con lo que las inequidades y arbitrariedades son inevitables.

Mirando al resto del mundo, estudiosos del fenómeno de la remuneración ligada al desempeño han concluido que: «... se impone prudencia sobre la remuneración ligada al desempeño. Intuitivamente es atractivo el vincular los pluses de productividad al desempeño anual de los funcionarios en términos de mediciones específicas de los resultados. Sin embargo, los hechos muestran que los pluses han tenido solamente una influencia marginal sobre el desempeño organizativo tanto en el sector privado como, especialmente, en el sector público, donde los resultados son difíciles de cuantificar. Instrumentos de remuneración ligada al desempeño introducen, además, un elemento de control político sobre el funcionario público... cuya imparcialidad queda perjudicada. Es casi imposible evitar la percepción de favoritismo incluso si el instrumento de evaluación del desempeño y su remuneración están bien administrados» (Schiavo-Campo 1996: 10-13).

\section{¿Qué se puede hacer?}

Quizás es conveniente recordar que el objetivo básico de cualquier instrumento de gestión del desempeño, y su evaluación y remuneración en la Administración pública, es la mejora del sistema de responsabilidad pública y el funcionamiento de las instituciones. Si consideramos la -más bien decepcionante- experiencia de más de 20 años de los países de la OCDE con la remuneración ligada al desempeño y los, todavía por ver, resultados de las nuevas prácticas de gestión del desempeño, quizás nos tengamos que preguntar si esos magros resultados valen realmente el esfuerzo. Es más, quizás nos tiente la pregunta de si es posible realmente mejorar la ejecutoria de las Administraciones públicas. 
Este tipo de preguntas requieren una reflexión mucho más compleja que la que estamos abordando en este artículo. Aquí nos limitamos a sostener que la introducción de esquemas de remuneración ligados al desempeño no es la solución -ni siquiera una solución entre otras- por los efectos negativos que produce en el sistema de función pública. En unos momentos en los que se trata de afianzar la transparencia y objetividad de las decisiones públicas si se quiere ganar la confianza del público, la introducción de más discrecionalidad no justificada puede tener efectos aún más contraproducentes.

Aún en el supuesto de que los instrumentos de evaluación y remuneración por objetivos funcionasen bien, cabría todavía preguntarse si el esfuerzo y los costes económicos asociados a un tal instrumento valen la pena y son asumibles por el presupuesto público. Una hipotética buena gestión de la paga ligada al desempeño implicaría una sofisticación administrativa de tal calibre que llevaría ineludiblemente a la multiplicación de la burocracia interna de las organizaciones públicas y eso va siempre en contra de la calidad del servicio al ciudadano y de la transparencia. Además, el gasto público en personal puede fácilmente salirse del control de los gestores públicos.

Todo ello no significa que la evaluación del desempeño de los funcionarios no deba hacerse o que no sea válida en la Administración pública, sino todo lo contrario. Esa evaluación se debe hacer y perfeccionar, pero sin ligarla a una remuneración o, en todo caso, garantizando que las consecuencias financieras de la evaluación sean muy pequeñas. El objetivo básico y principal de la evaluación del desempeño debe ser el desarrollo profesional del funcionario, algo que no necesariamente tiene que ir ligado a más salario, a condición de que la remuneración fija sea estable y suficiente en comparación con el coste de la vida. Como hemos expuesto más arriba, algunos gobiernos en el centro y este de Europa, pero no sólo, han estado utilizando la parte variable del salario como una excusa para no aumentar las remuneraciones de los funcionarios hasta unas cantidades dignas y compatibles con la necesaria profesionalización de la función pública.

La evaluación del desempeño se puede, con relativa facilidad, usar como base para el desarrollo profesional del funcionario si se hace bien y se toma en serio como un instrumento de gestión de recursos humanos. Por ejemplo, se pude utilizar para fundamentar las promociones, para orientar las actividades de formación individuales y para evaluar las necesidades de formación a nivel colectivo de una unidad o ministerio, o para animar la movilidad horizontal tratando de encontrar el mejor puesto para las capacidades de cada funcionario. Todo esto tiene como necesaria condición el que la función de dirección de recursos humanos en la Administración tiene que desarrollarse más y consolidarse como una función clave del sistema de función pública en cualquier país. La función gestión de recursos humanos necesita adquirir una importancia más central en la Administración, al menos al mismo nivel que la función de gestión presupuestaria y de recursos financieros.

Un aspecto particularmente positivo de la evaluación del desempeño es que puede conducir a diálogos regulares y constructivos entre superiores y subordinados sobre los objetivos de la organización pública y sobre el papel que cada individuo puede jugar en la consecución de esos objetivos. Ese diálogo, si es inteligentemente llevado y gestionado por los superiores, puede dar a los funcionarios un redoblado sentido de pertenencia y de participación y esto es una condición para estimular la creatividad en su contribución personal a los fines de la institución de que se trate. Los superiores o los gestores pueden también considerar este diálogo como un instrumento de gestión de personal orientado a afianzar el compromiso de los funcionarios con los objetivos de la institución. De hecho, los informes citados anteriormente de la UE en 2002 y de la OCDE en 2005 coinciden en este aspecto al considerar como positivo el diálogo entre superiores y subordinados que se establece con ocasión de la evaluación regular y periódica del desempeño. 
Lo que es crucial en todo caso es que los ejercicios de evaluación de desempeño se diseñen y se practiquen de modo que su legitimidad esté fuera de toda duda razonable. Esto implica muchas cosas. Entre otras, lo siguiente: que la asignación interna de responsabilidades y tareas sea equilibrada y justa; que el sistema de selección de objetivos sea transparente y negociado con el funcionario interesado; que la evaluación se haga por un procedimiento preestablecido y de acuerdo con una clara normativa; que haya posibilidad de impugnar la evaluación tanto en cuanto a procedimiento como a resultado y tanto ante instancias internas a la organización como externas a la misma; que haya garantías suficientes de que los resultados de la evaluación serán correctamente utilizados y no para fines distintos de los que están previstos en la normativa.

En conclusión, la evaluación del desempeño debería ser una práctica corriente en la Administración pública que no necesariamente tiene que tener consecuencias financieras para el funcionario. El desarrollo de las técnicas de evaluación de recursos humanos es menos costoso que la introducción de remuneración ligada al desempeño y no produce efectos perniciosos, sino que puede producir efectos positivos sobre la ejecutoria individual de los funcionarios y colectiva de las instituciones públicas. Naturalmente, el éxito dependerá del grado de profesionalización de los gestores de recursos humanos dentro de la Administración, pero de eso no corresponde hablar en este artículo.

\section{REFERENCIAS BIBLIOGRÁFICAS ${ }^{*}$}

A Fresh Start for Federal Pay: The Case of Modernisation White Paper.(2002). Washington: US Government Printing Office.

OECD/PUMA (1994), «Public Service Pay Determination and Pay Systems in OECD Countries». Occasional Papers 2. Paris.

OECD/PUMA (1996), Integrating People Management into Public Service Reform. Paris.

OECD/PUMA (1996), «Pay Reform in the Public Service. Initial Impact on Pay Dispersion in Australia, Sweden and the United Kingdom», Occasional Papers 10. Paris.

OECD/PUMA (1997 a), «Performance Pay Schemes for Public Sector Managers. An Evaluation of the Impact», Occasional Papers 15. Paris.

OECD/PUMA (1997 b), Trends in Public Sector Pay in OECD Countries. Paris.

OECD/PUMA (1998), «Wage Determination in the Public Sector. A France / Italy Comparison», Occasional Papers 21. Paris.

OECD Public Governance and Territorial Development Directorate, (2005), Performance-Related Pay Policies for Government Employees. Paris.

Pollit, Ch y Bouckaert, G. (2000), Public Management Reform. A Comparative Analysis. Oxford: Oxford University Press.

Schiavo-Campo, S. (1996), «Reforming the Civil Service», Finance \& Development 33-3.

(*) Algunas publicaciones de a OCDE están disponibles en www.oecd.org. 